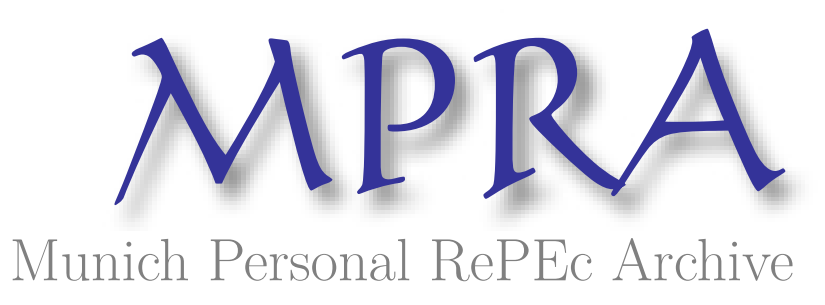

\title{
Money Multipliers and the Slopes of IS and LM: Comment
}

Cebula, Richard

Jacksonville University

30 January 1984

Online at https://mpra.ub.uni-muenchen.de/51515/

MPRA Paper No. 51515, posted 17 Nov 2013 16:59 UTC 


\section{Money Multipliers and the Slopes of IS and LM: Comment*}

\section{l. Introduction}

In a recent issue of this Journal, Meyer [3] develops a model in which he examines the impact of the relative slopes of the IS and LM curves on economic policy effectiveness when the IS curve is negatively sloped. This brief note extends Meyer's analysis by examining the same issue under the condition that the IS curve is positively sloped. ${ }^{1}$

\section{Analysis}

Following Meyer [3], we deal for simplicity with linear relationships. The commodity market is described by:

$$
Y=(A o-e i-f i) /(1-b-d)
$$

where $A O$ is autonomous spending, $b$ is marginal propensity to consume, $d$ is the marginal propensity to invest, $Y$ is real income, $i$ is the interest rate, $(-e)$ is the interest responsiveness of investment, and $(-f)$ is the interest responsiveness of consumption. The present model differs from that in Meyer [3] by its inclusion of the marginal propensity to invest and the interest responsiveness of consumption. The slope of the IS curve is given by:

$$
S_{I S}=-(1-b-d) /(e+f) \gtreqless 0 \quad \text { as } \quad d \gtreqless(1-b) .
$$

The money market is given by:

$$
M O=h+k Y-j i
$$

where $M O$ is the autonomous money supply, $h$ is a constant, $(-j)$ is the interest responsiveness of money demand, and $k$ is the transactions coefficient. The slope of the LM curve is given by:

$$
S_{L M}=k / j>0 \text {. }
$$

For the case where the slope of the IS curve is positive, stability requires that:

$$
k / j>-(1-b-d) /(e+f)
$$

Such stable equilibria are represented in Figure 1.

Refer in Figure 1 first to the $L M$ curve labelled $L M^{\prime}$. The given $I S$ curve intersects $L M^{\prime}$ at income level $Y_{0}$ and interest rate $i_{0}$. Now let the money stock increase. This policy

*The author is indebted to an anonymous referee for very helpful comments and suggestions.

1. The case of the positively sloped IS curve has received considerable attention in recent years. See Burrows [1], Cebula [2], Silber [4], Steind! [5] and Wang [6]. 


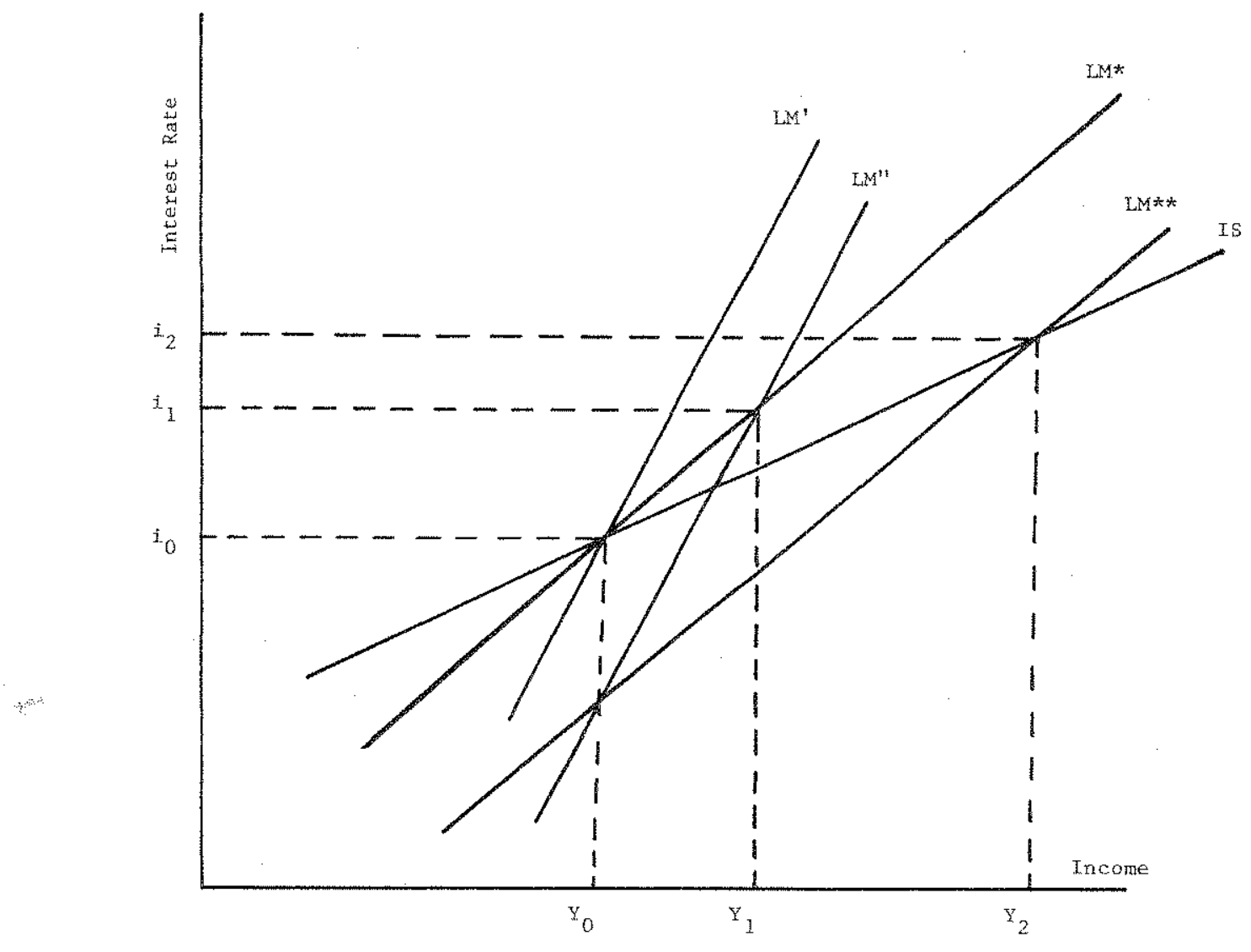

Figure

action shifts the $L M$ curve downwards from $L M^{\prime}$ and to $L M^{\prime \prime}$ and raises the income level to $Y_{1}$ and the interest rate to $i_{1}$.

Refer now to the curve $L M^{*}$, which (like $L M^{\prime}$ ) intersects the $I S$ curve at income $Y_{0}$ and interest rate $i_{0}$. Let the money stock increase by identically the same amount as above. The impact of this policy is to shift the $L M$ curve from $L M^{*}$ to $L M^{* *}$. The monetary policy in question in this case raised the income level from $Y_{0}$ to $Y_{2}$ and the interest rate from $i_{0}$ to $i_{2}$.

Clearly, the results above illustrate that, in the case of the positively sloped IS curve, the effectiveness of monetary policy always rises as the slope of the LM curve declines. That is, the value of $d Y / d M 0$ (and of di/dMO) always increases as the slope of the LM curve decreases so long as (a) the sign of $-(1-b-d) /(e+f)>0$ and (b) the $\mathbb{I S} / \mathrm{LM}$ equilibrium is stable. This finding actually is compatible with the results for the negatively sloped IS curve in Meyer [3, 228], who asserts that:

The money multiplier is positively related to the slope of the LM curve only if the absolute value of the product of the slopes of the LM and IS curves exceeds unity. A flatter LM curve actually increases the money multiplier when the slope of the LM curve is less than the absolute value of the inverse of the slope of the IS curve . . a steeper LM curve increases the money multiplier only if the ... angle between the IS and LM curves exceeds $90^{\circ}$.

In other words, in the case of a positively sloped IS curve, the difference between the slopes of the IS and LM curves is less than $90^{\circ}$; hence, in this circumstance, Meyer's [3] argument can be extended beyond the case of the negatively sloped IS curve. 
The finding derived above can be confirmed mathematically. Solving the system (1) through (4) for the general equilibrium level of income yields:

$$
Y=\left[j A_{o}-(e+f)(h-M o)\right] /[j(1-b-d)+k(e+f)] .
$$

In turn, the money multiplier is

$$
d Y / d M_{0}=(e+f) /[j(1-b-d)+k(e+f)] .
$$

Finally, the impact of the slope of the LM curve upon the money multiplier is provided by the following:

$$
\begin{aligned}
d(d Y / d M o) / d S_{L M}= & (e+f)(1-b-d)[-(e+f) /(1-b-d)+k / j] \\
& / j[j(1-b-d)+k(e+f)]^{2}<0 .
\end{aligned}
$$

Thus, as argued above, for the case of the positively sloped IS curve, the effectiveness of monetary policy always rises as the slope of the LM curve declines. ${ }^{2}$

\section{Conclusion}

For the case of the positively sloped IS curve (and a stable IS-LM equilibrium), it can also be shown that the effectiveness of monetary policy always is greater if the slope of the IS curve is greater, i.e., $d Y / d M 0$ (and $d i / d M 0$ ) rises as the slope of the $1 \mathrm{~S}$ curve rises. This finding also is compatible with Meyer [3]. Finally, in the case of the positively sloped IS curve, it can be illustrated that fiscal policy effectiveness is greater the flatter the LM curve or the steeper the IS curve: that is, $d Y / d A 0$ (and $d i / d A 0$ ) rises as the slope of the $\mathrm{LM}$ curve decreases or the slope of the IS curve increases. Thus, in the case of fiscal policy effectiveness with a positively sloped IS curve, Meyer's [3] arguments apply for the LM curve but not for the IS curve.

Richard J. Cebula Emory University Atlanta, Georgia

2. In (8), the denominator is clearly positive. Given a positively sloped IS curve and stability, the bracketed term in the numerator also is positive. Since the IS curve is positively sioped, the term $(1-b-d)$ is negative. Given $(e+f)>0$, the negative value in $(8)$ is thus unequivocal.

\section{References}

1. Burrows, Paul, "The Upward Sloping IS Curve and the Control of Income and the Balance of Payments." Journal of Finance, June 1974, 955-61.

2. Cebula, Richard J., "A Brief Note on Economic Policy Effectiveness." Southern Economic Journal, October $1976,1174-76$. $226-29$.

3. Meyer, Paul A., "Money Multipliers and the Slopes of IS-LM." Southern Economic Journal, July 1983.

4. Silber, William L., "Monetary Policy Effectiveness: The Case of the Positively Sloped IS Curve," Journal of" Finance, December 1971, 1023-31. 69.

5. Steindl, Frank, "Giffen Goods, IS Curves, and Macroeconomic Stability." Metroeconomica, June 1970, 165 --

6. Wang, Leonard F. S., "IS-LM Stability and Economic Policy Effectiveness: Further Observations." Journal of Macroeconomics, Spring 1980, $181-83$. 